\title{
The association between attention-deficit/hyperactivity (ADHD) symptoms and self-employment
}

\author{
Ingrid Verheul $^{1,5}$ - Wim Rietdijk ${ }^{2,3} \cdot$ Joern Block $^{4,5} \cdot$ Ingmar Franken $^{6}$. \\ Henrik Larsson ${ }^{8,9} \cdot$ Roy Thurik $^{2,3,5,7}$
}

Received: 24 February 2015/Accepted: 4 May 2016/Published online: 13 May 2016

(c) The Author(s) 2016. This article is published with open access at Springerlink.com

\begin{abstract}
Attention-deficit/hyperactivity (ADHD) symptoms have been associated with the decision to become self-employed. Although these symptoms are generally regarded as disadvantageous, there may also be a bright side. To our knowledge, however, there has been no systematic, epidemiological evidence to support this claim. This paper examines the association between ADHD symptoms and self-employment in a population-based sample from the STAGE cohort of the Swedish Twin Registry $(\mathrm{N}=7208)$. For replication, we used a sample of Dutch students who participated in the Global University Entrepreneurial Spirit Students' Survey $(\mathrm{N}=13,112)$. In the Swedish sample, we found a positive association with
\end{abstract}

Ingrid Verheul

iverheul@rsm.nl

1 Rotterdam School of Management, Erasmus University Rotterdam, P.O. Box 1738, 3000 DR Rotterdam, The Netherlands

2 Erasmus School of Economics, Erasmus University Rotterdam, Rotterdam, The Netherlands

3 Institute for Behavior and Biology (EURIBEB), Erasmus University Rotterdam, Rotterdam, The Netherlands

4 Professur für Unternehmensführung, Universität Trier, Trier, Germany

5 Erasmus Research Institute of Management (ERIM), Erasmus University Rotterdam, Rotterdam, The Netherlands

6 Institute of Psychology, Erasmus University Rotterdam, Rotterdam, The Netherlands

7 Montpellier Business School, Montpellier, France

8 Department of Medical Epidemiology and Biostatistics, Karolinska Institutet, Stockholm, Sweden

9 Karolinska Institutet Center of Neurodevelopmental Disorders (KIND), Stockholm, Sweden self-employment for both general ADHD symptoms [odds ratio (OR) 1.13 ; $95 \%$ confidence intervals (CI) 1.04-1.23] and hyperactivity symptoms [OR $1.19 ; 95 \%$ CI 1.08-1.32], whereas no association was found for attention-deficit symptoms [OR 0.99; $95 \%$ CI 0.89-1.10]. The positive association between hyperactivity and self-employment was replicated in the Dutch student sample [OR 1.09 ; $95 \%$ CI 1.03-1.15]. Our results show that certain aspects of ADHD, in particular hyperactivity, can have a bright side, as they are positively associated with selfemployment.

Keywords Attention-deficit - Hyperactivity - Symptoms . ADHD · Self-employment

\section{Introduction}

Prominent entrepreneurs have publicly credited their attention-deficit hyperactivity (ADHD) symptoms as a driver of their decision to become self-employed [1-3]. Examples include Ingvar Kamprad (founder of IKEA) and Richard Branson (founder of the Virgin Group) [2, 3]. The Economist recently published a short article addressing the suitability of self-employment for people who experience ADHD symptoms [4].

ADHD is a neurodevelopmental disorder characterised by attention-deficit and hyperactivity [5-7]. The onset of ADHD is typically during childhood (before the age of 12), and it is therefore often regarded as a childhood disorder. Studies following children with a diagnosis of ADHD have shown that ADHD symptoms are persistent over time, at least into early adulthood [6,8-11], with $65 \%$ of individuals still having a full ADHD diagnosis or partial remission at the age of 25 [12]. Recent research has 
devoted more attention to increasing our understanding of the persistence of ADHD symptoms in (young) adults [13]. Furthermore, the most recent DSM criteria were adjusted to enable a diagnosis across the lifespan and not only during childhood [14].

Although prior research has mainly focused on the negative consequences of ADHD for individual performance in formal education and wage employment [15-19], recent studies have highlighted positive aspects of ADHD symptoms, such as its association with resilience and wellbeing [20], close friendship [21], and third-party inferences about an individual's generative qualities (being creative, visionary, good at generating ideas) [22]. In the present study, we focus on a potential positive aspect of ADHD: self-employment as a career choice. Self-employment is not just any career choice but is a manifestation of entrepreneurship that is essential for employment creation, innovation and the economic growth of modern societies $[23,24]$. It can be used as an economic instrument in the business cycle [25] and to lift people out of unemployment [26].

In the popular press, it has been suggested that individuals with ADHD symptoms are able to break through organisational inertia due to their ability to envision and create new 'realities' and (successfully) start their own ventures [2-4]. Allegedly, when individuals who experience ADHD symptoms succeed in developing mechanisms to cope with their 'weaknesses', they would be able to exploit their extraordinary talents and perform just as well as or even better than their peers in business [2, 27, 28]. Academic research has found only circumstantial evidence linking ADHD symptoms to self-employment when examining the association with entrepreneurial intentions [29], creativity [30-32], risk-taking [33], and proactivity [5]. To our knowledge, there is no systematic, epidemiological evidence supporting a link between ADHD symptoms and self-employment.

The present study was designed to examine the association between self-reported ADHD symptoms and self-employment in a population-based sample of 7208 individuals from the STAGE cohort of the Swedish Twin Registry of the Karolinska Institute. The findings were replicated in a sample of 13,119 students participating in the Global University Entrepreneurial Spirit Students' Survey (GUESSS) 2011 in the Netherlands. Given the discussions in the (popular) literature and the circumstantial scholarly evidence, we expected a positive association between ADHD symptoms and the decision to become self-employed [1-4, 29]. We should emphasise that the present study does not focus on ADHD as a full-blown psychiatric disorder. For the purpose of the present research, self-reported psychiatric symptoms are defined along a continuum [34] and not as a psychiatric classification.

\section{Method}

\section{Swedish twin registry: STAGE cohort as the discovery sample}

We used the STAGE (Swedish Twin Studies on Adults: Genes and Environment) cohort from the Karolinska Institute in Stockholm, Sweden, as the discovery sample. The STAGE cohort is part of the population-representative Swedish Twin Registry (STR), which was established in the 1950s to study the effects of smoking and drinking on cancer and cardiovascular diseases [35]. At present, the STR contains rich data about biological and clinical markers together with the socio-economic background of twins living in Sweden [35]. For a full account of the design and execution of the STR project and details of the ADHD data in the STAGE cohort, we refer to Lichtenstein et al. [35] and Larsson et al. [10], respectively.

All twins born between 1959 and 1985 (a total of 42,582 twins) received an invitation letter with information about the project in May and June 2005. The response rate was $59.6 \%(\mathrm{~N}=25,364,56 \%$ female, age [mean] $=41.56$, age $[\mathrm{sd}]=7.6)$. The entire questionnaire contained approximately 1300 questions, of which the respondents answered 800-900 questions on average [35]. Dropouts could be explained by a general unwillingness to respond to a lengthy survey [10]. Non-respondents were significantly more often male, had at least one parent born outside Sweden, and were more likely to have been diagnosed with a psychiatric disorder and convicted of any type of crime [10, 36, 37], which may indicate that the most severe cases did not respond to the questionnaire. This limits generalisations to the more severe cases of the ADHD spectrum. Informed consent was obtained from all individual participants included in the study. This project was reviewed and approved by the ethics committee of the Karolinska Institute.

\section{Self-employment measure}

Participants answered two questions about their involvement in self-employment: whether they were self-employed full-time (yes/no) and whether they were selfemployed part-time (yes/no). We constructed one measure of self-employment (yes/no), which was coded 1 if the participant was self-employed part-time or full-time and 0 if (s)he was not self-employed. In the STAGE cohort, 14,039 out of 25,364 participants $(\approx 55 \%$ ) provided their self-employed status (yes/no). A total of 2096 participants $(\approx 14 \%)$ were self-employed, of whom $1270(\approx 9 \%)$ were self-employed full-time and $826(5 \%)$ were selfemployed part-time. Three participants answered 'yes' to both the part-time and full-time self-employment question 
and were excluded from the analysis. Furthermore, we randomly dropped one twin from each pair because their similarity would violate the assumption of independent observations, resulting in a final sample of 7208 participants $(58 \%$ female, age $[$ mean $]=43.9$, age $[\mathrm{sd}]=6.7)$. Of these respondents, a total of $897(\approx 12 \%)$ were self-employed, of whom $515(\approx 7 \%)$ were self-employed fulltime and $382(\approx 5 \%)$ were self-employed part-time, which was similar to the total sample distribution.

\section{Attention-deficit/hyperactivity (ADHD) symptoms measure}

ADHD symptoms were assessed using the Adult ADHD Self-Report Scale (ASRS-v1.1), which consists of 18 items reflecting the DSM-IV-TR criteria [10]. Attention-deficit symptoms and hyperactive symptoms were measured by 9 items each. ${ }^{1}$ Answers for each item were given on a 3-point Likert scale $(0=$ 'no'; $1=$ 'yes, to some extent'; and $2=$ 'yes'). The 18 ASRS-v1.1 items were slightly modified to allow for the assessment of ADHD symptoms in adults [35]. As can be expected from a non-clinical population sample, many participants reported having no or few ADHD symptoms. The average percentage of respondents reporting inattentive symptoms and hyperactive symptoms (with the answer 'yes') was 3.6 and $4.6 \%$, respectively. Approximately one-third of the respondents reported no symptoms [10]. This result closely resembles the prevalence rate of adult ADHD reported in Kessler et al. [38].

The symptom scores were added to create a scale of ADHD symptoms and two sub-scales of attention-deficit and hyperactivity [10]. Values for the reliabilities of these three scales in our sample were $\alpha=0.84, \alpha=0.78$, and $\alpha=0.78$, respectively. These reliabilities were similar to those reported in Larsson et al. [10]. Because the three scales were highly skewed (skewness: ADHD, 1.66; attention-deficit, 1.77; hyperactivity, 1.72), the scales were $\log$-transformed $(\log 10[x+1]$, where $x$ is the initial value) to normalise their distributions (skewness after $\log$ transformation: ADHD, -0.16; attention-deficit, 0.27; hyperactivity, 0.26). As indicated in Larsson et al. [10, p. 199], the sum score of the 18 ADHD items used in this study yielded results similar to those reported in other studies using self- or parent-reported measures of ADHD.

\section{Control variables}

In the STAGE cohort, we included the following demographic variables: age, gender, and whether the participant

\footnotetext{
1 Throughout the paper we refer to hyperactivity symptoms, although the ASRS v1.1 measure is slightly broader given that it includes three items related to impulsivity.
}

attended university $(0=$ no, $1=$ yes $)$ as an initial test to control for additional effects.

\section{GUESSS study: replication}

We attempted to replicate the analysis linking ADHD symptoms to self-employment in a student sample from the Global University Entrepreneurial Spirit Students' Survey (GUESSS) $^{2} 2011$ in the Netherlands. GUESSS is an international research consortium that studies the career objectives of students in higher education. In the Netherlands, students at 14 universities and 24 polytechnics received a link to the online survey through email. After 1 month, a reminder was sent. Two randomly drawn participants received an iPad 2.0 to reward their participation. To prevent self-selection of students with entrepreneurial intentions, the topic of the survey was announced as future career paths. The GUESSS Netherlands study was in line with the Erasmus Research Institute of Management review board's standards and did not include clinical or patient data [29].

The response rate for the GUESSS study was $7.6 \%$ for educational institutions that systematically recruited participants [29], leading to an overall database of 13,119 students $(56 \%$ female, age [mean] $=22.96$, age $[\mathrm{sd}]=0.49$ ), of whom 374 were student entrepreneurs (i.e., reported having their own business during their studies). Comparing the GUESSS Netherlands sample with the global GUESSS sample reported in Sieger et al. [39], we found that our (Dutch) sample was representative in terms of socio-demographic characteristics and the prevalence of student entrepreneurs. Specifically, in our sample, $56 \%$ of the respondents were female compared to a global average of $55.2 \%$, and the average age of 23 was within the mid-range age of the international average, which is between 20 and 27 years [39]. Furthermore, $2.9 \%$ of the students in our study had their own company, compared to a global average of $2.5 \%$ student entrepreneurs [39].

In the GUESSS study, self-employment was measured as a dichotomous variable indicating whether students were self-employed in their own founded firm during their studies. ADHD symptoms were measured using the six-item Adult ADHD Self-Report Scale v1.1 (ASRS v1.1) screener, developed by Kessler et al. [38, 40], which consists of the six most predictive ADHD symptoms of the 18 DSM-IV-TR criteria used in the STAGE study. This enabled us to replicate the analysis in the STAGE cohort. Each item was answered on a 5 -point Likert scale $(1=$ never to $5=$ always). Although the measures were different, the screener and the full 18-item measure were found to be highly

\footnotetext{
${ }^{2}$ For more information about GUESSS, we refer to http://www. guesssurvey.org.
} 
correlated [38, 40]. Average scores were computed for ADHD symptoms (based on six items, $\alpha=0.59$ ), attentiondeficit (based on four items, $\alpha=0.62$ ), and hyperactivity (based on two items, $\alpha=0.43$ ). Although these scales had low to moderate reliability, they were still close to the lower bound of reported reliabilities for the ASRS screener questions in Kessler et al. [40] (see Verheul et al.) [29]. The three scales were only moderately skewed: sample skewness for the ADHD symptom scale, the attention-deficit scale, and the hyperactivity scale amounted to $0.21,0.35$, and 0.06 , respectively, with a standard error of 0.02 . These skewness measures indicated that log-transformation of the variables was not necessary. Given that the GUESSS study consisted of only students from universities and polytechnics, we only included age and gender as control variables in the model.

\section{Statistical analysis}

To examine the association between ADHD symptoms and self-employment, we estimated binary logistic regressions. First, in the STAGE cohort, we examined the association between the sum score on the DSM-IV diagnostic criteria items for all ADHD symptoms (18 items), attention-deficit and hyperactivity symptoms (each 9 items), and self-employment (part-time/full-time). Second, we replicated this analysis using data from the GUESSS study. Specifically, we estimated the associations between the sum score on the ASRS-6 v1.1 screener items for all ADHD symptoms (6 items), attention-deficit symptoms (4 items), hyperactivity symptoms ( 2 items), and self-employment. We report the effect sizes in terms of odds ratios (OR) and the associated $95 \%$ confidence intervals ( $95 \% \mathrm{CI}$ ). In the tables, we denote statistical significance ( $p$ values at 5,1 , and $0.1 \%$ levels, respectively) using asterisks $\left(*, * *\right.$, and ${ }^{* *}$, respectively).

\section{Results}

\section{STAGE cohort}

In Table 1, we present the results of the binary logistic regressions explaining self-employment (part-time/fulltime). We found a positive association with self-employment for both general ADHD symptoms (OR 1.13; $95 \%$ CI 1.04-1.23) and hyperactivity symptoms (OR 1.19; $95 \%$ CI 1.08-1.32) but not for attention-deficit symptoms (OR $0.99 ; 95 \%$ CI $0.89-1.10$ ).

\section{GUESSS study: replication}

We attempted to replicate the association between ADHD symptoms and self-employment using the GUESSS 2011 data. The results of the binary logistic regressions are
Table 1 STAGE cohort; Binary logistic regressions with self-employment (part-/full-time) as dependent variable and general ADHD symptoms, and the two sub-scales attention-deficit symptoms and hyperactivity symptoms as independent variables
(1)
(2)

\begin{tabular}{lll}
\hline General ADHD symptoms & $\begin{array}{l}1.13^{* *} \\
(1.04-1.23)\end{array}$ & \\
Attention-deficit symptoms & & 0.99 \\
& & $(0.89-1.10)$ \\
Hyperactivity symptoms & & $1.19 * * *$ \\
& & $(1.08-1.32)$ \\
$\mathrm{N}$ & 7208 & 7208 \\
Log-likelihood & -2599 & -2597 \\
df & 4 & 5 \\
Chi-square & 209.2 & 222.7 \\
Pseudo R-square & 0.04 & 0.04 \\
\hline
\end{tabular}

The coefficients are odds ratios (ORs) and $95 \%$ confidence intervals (CI) are in parentheses; *** $p<0.001, * * p<0.01, * p<0.05$

Both models control for age, gender, and university education $(0=$ no and $1=$ yes $)$

presented in Table 2. We found no evidence of an association between general ADHD symptoms and self-employment (OR 1.00; $95 \%$ CI 0.97-1.02). However, when we separated attention-deficit and hyperactivity, we found a negative association between self-employment and attention-deficit symptoms (OR 0.95; $95 \%$ CI 0.92-0.99) and a positive association between self-employment and hyperactivity symptoms (OR 1.09; $95 \%$ CI 1.03-1.15).

To summarise, we found a positive association between (general) ADHD symptoms and self-employment in the STAGE cohort that could not be replicated (i.e.,

Table 2 GUESSS study; Binary logistic regressions with self-employment (part-/full-time) as dependent variable and general ADHD symptoms, and the two sub-scales attention-deficit symptoms and hyperactivity symptoms as independent variables

\begin{tabular}{lll}
\hline & $(1)$ & $(2)$ \\
\hline General ADHD symptoms & 0.99 & \\
& $(0.93-1.07)$ & \\
Attention-deficit symptoms & & $0.89^{*}$ \\
& & $(0.79-1.00)$ \\
Hyperactivity symptoms & & $1.13^{*}$ \\
& & $(1.00-1.28)$ \\
N & 13,119 & 13,119 \\
Log-likelihood & -3189 & -3183 \\
df & 3 & 4 \\
Chi-square & 208.5 & 214.8 \\
Pseudo R-square & 0.07 & 0.07 \\
\hline
\end{tabular}

The coefficients are odds ratios (ORs) and $95 \%$ confidence intervals (CI) are in parentheses; *** $p<0.001, * * p<0.01, * p<0.05$

Both models control for age, and gender 
insignificant) in the GUESSS study. Furthermore, the association between attention-deficit symptoms and selfemployment was significantly negative in the GUESSS study and insignificant in the STAGE cohort. Finally, the association between hyperactivity symptoms and self-employment was significantly positive in both the STAGE cohort and the GUESSS study.

\section{Sensitivity and additional analyses}

We performed a series of sensitivity analyses using both the STAGE and GUESSS data. First, we reran the logistic regressions using the entire STAGE database, including pairs of twins instead of randomly dropping one twin, and clustered the standard error at the family level to account for the joint characteristics of twins. In the larger sample of approximately 11,000 respondents, the association between ADHD symptoms and self-employment remained intact (OR 1.23; $95 \%$ CI 1.13-1.34). Furthermore, the results of the sub-scales remained stable: attention-deficit was not significantly associated with self-employment (OR 1.02; $95 \%$ CI 0.94-1.11), and hyperactivity was positively associated with self-employment (OR 1.19; $95 \%$ CI $1.10-1.29) .^{3}$

Second, to compare the results of the GUESSS study with those of the STAGE cohort, we examined the associations between ADHD symptoms and self-employment in the STAGE cohort using the 6 items from the ASRS- 6 v1.1 screener instead of the 18 item ASRS-v1.1 score. In line with the GUESSS findings, we found no evidence of a significant association between general ADHD symptoms and self-employment (OR 1.04; $95 \%$ CI 1.00-1.09). However, we did not find support for a significant (negative) association between self-employment and attentiondeficit symptoms (OR 0.97; $95 \%$ CI 0.9-1.03). We did find a positive association between hyperactivity symptoms and self-employment (OR 1.04; $95 \%$ CI 1.00-1.09), which is in agreement with the analyses. ${ }^{4}$

Third, we examined the association between ADHD symptoms and self-employment using a stricter definition of ADHD that was closer to an actual psychiatric diagnosis

\footnotetext{
${ }^{3}$ For the analyses including the ADHD symptom scale (plus controls), the log pseudo likelihood was -2705 , the pseudo R-square was 0.06, and the Wald Chi-square was 319.4. Standard errors were adjusted for 8434 clusters in pair ID (identifying twins). For the analyses separating attention-deficit and hyperactivity, the log pseudo likelihood amounted to -4118 , the pseudo R-square was 0.04 , and the Wald Chi-square was 354.8. Standard errors were adjusted for 8771 clusters in pair ID.

${ }^{4}$ In line with Kessler et al. [38, 40], the reliability coefficients (Cronbach's alpha) for general ADHD symptoms, attention-deficit symptoms and hyperactivity symptoms were $0.59,0.58$, and 0.50 , respectively, indicating that the scales were moderately reliable.
}

[10]. In the STAGE data, we used the "strict criteria" score: in the responses to the DSM-IV 18 items, 1 ("yes") was recoded to yes and 2 or 3 ("yes, to some extent" or "no") were recoded to no. The outcomes supported those of the initial analysis. The association between ADHD symptoms and self-employment became stronger (OR: $1.35 ; 95 \%$ CI 1.00-1.81), which was also true for hyperactivity (OR: 1.54; $95 \%$ CI 1.03-2.29). In the GUESSS data, for each of the ASRS-6 v1.1 items, we examined whether the score was beyond the threshold level ('yes $=1$ ' and 'no' $=$ ' 0 ') and constructed new scale variables for ADHD symptoms, attention-deficit and hyperactivity based on the sum of the dummy $(0,1)$ scores on six, four and two items, respectively. The findings remained stable for ADHD symptoms (not significant, OR: $1.00 ; 95 \%$ CI 0.93-1.07), attention-deficit (significant, OR: $0.90 ; 95 \%$ CI $0.82-0.98$ ), and hyperactivity (significant, OR: 1.27; $95 \%$ CI 1.11-1.47).

Fourth, we re-estimated the logistic regressions including additional control variables. Specifically, because unemployment is an important push factor for self-employment [26] and because individuals who experience ADHD symptoms have a higher chance of unemployment $[38,41]$, we added a control variable in the analyses with the STAGE data that captured whether the individual had mainly been unemployed or hardly worked in the 3 years preceding the survey. The association between ADHD and self-employment remained positive and significant (OR: 1.15 ; $95 \%$ CI $1.06-1.25)$. This was also true for hyperactivity (OR: 1.19; $95 \%$ CI 1.07-1.32). Furthermore, we controlled for personality characteristics of people with ADHD symptoms. We included measures for extraversion and neuroticism to account for the fact that ADHD symptoms have been linked to (higher) neuroticism [42, 43] and extraversion [44]. These Big Five Factor traits have also been linked with self-employment [45, 46]. When controlling for these two personality factors, both general ADHD symptoms (OR: 1.17; $95 \%$ CI 1.06-1.29) and hyperactivity (OR: $1.14 ; 95 \%$ CI 1.02-1.28) remained significantly positive. In the analyses with the GUESSS data, we were able to control for factors that are generally associated with self-employment status, including selfemployed parents, study field and level. In particular, parental role models have been linked with the decision to become self-employed [47, 48]. Accounting for the aforementioned factors in the analyses, the results were stable, and only attention-deficit and hyperactivity were significantly associated with self-employment (attention-deficit, OR: 0.96; $95 \%$ CI 0.92-0.99; hyperactivity, OR: 1.07; $95 \%$ CI 1.01-1.13).

Overall, the association between ADHD symptoms and self-employment remained intact but became insignificant when more controls were added. In the STAGE data, this 
was the case when considering whether someone was mainly wage employed in the past 3 years. This is not surprising given the fact that approximately $60 \%$ of the respondents were currently wage employed and had mainly been working in wage jobs in the past 3 years. In the GUESSS data, the association between ADHD symptoms and self-employment appeared sensitive to the inclusion of career motives (e.g., challenge, realising a dream, income, financial security, innovation, opportunity exploitation, high position, flexibility, own boss, social mission), which may be related to the importance of the person-occupation fit for individuals with ADHD symptoms [29].

Finally, using the STAGE data, we tested for linkages between ADHD symptoms and other occupations. The findings showed no association with wage employment (OR: 0.96; $95 \%$ CI 0.90-1.03), suggesting that a regular wage job may not be as suitable as self-employment for people with high levels of ADHD symptoms. Together with our finding that ADHD symptoms are positively associated with unemployment (OR: 1.24; $95 \%$ CI 1.12-1.37), we are unable to reject a potential push effect by which people with ADHD symptoms become self-employed because of a lack of (suitable) alternative occupations.

\section{Discussion}

The present study moved beyond the clinical view of ADHD as a pathological disorder and used the symptoms of ADHD across the entire measurement spectrum to examine a potentially positive aspect: the association of ADHD with the involvement in self-employment. Hence, the aim of this study was not to diagnose individuals with ADHD and then examine the viability of self-employment as a career option. Instead, we investigated whether individuals who exhibit higher levels of ADHD symptoms-but who do not necessarily screen positive for ADHD in a clinical sense-are positively associated with self-employment. In line with previous research, special attention was paid to whether this association involved general ADHD symptoms or the separate attention-deficit and hyperactivity symptom dimensions [10, 34, 49-51].

The present research is part of a series of investigations on the relation between ADHD and entrepreneurship. In Verheul et al. [29], the intention to become self-employed was found to be associated with ADHD symptoms in a survey of Dutch students. In Thurik et al. [52], the entrepreneurial orientation, measured using innovativeness, risk aversion and proactivity [53], was found to be associated with ADHD symptoms in a survey of French business owners. The present study investigates involvement in selfemployment. All three studies report a positive association, although the hyperactivity part seems to dominate. Future studies should also take into account entrepreneurial performance, such as growth, profits, longevity, and satisfaction.

Two independent samples were used for the present analysis: Swedish adults (STAGE cohort) and Dutch students (GUESSS study). In the Swedish sample, we found a positive association of both general ADHD symptoms and hyperactivity symptoms with self-employment, whereas this association could not be found for attention-deficit symptoms. The positive association between hyperactivity symptoms and self-employment was replicated in the Dutch sample. The effects remained intact in a series of sensitivity analyses.

ADHD is typically characterised by high energy levels that are expressed as severe and persistent attention-deficit and hyperactivity and that are driven by behavioural 'disinhibition' or a lack of restraint [22, 41, 54]. Less attention is paid to ADHD symptoms for adult decision-making [55], but it is generally recognised that high levels of attentiondeficit and hyperactivity have negative consequences in the workplace. Individuals who demonstrate such behaviours tend to show low job performance and a high chance of becoming unemployed [56-58]. However, the present results show that ADHD symptoms, particularly hyperactivity, are associated with aspects that may be beneficial for the individual and society at large.

The present study has implications for further research. Our results may be an initial step towards establishing a link between ADHD symptoms and career choices, such as self-employment, or other manifestations of entrepreneurship. The outcomes of this study may help to 'destigmatise' ADHD as a disorder, particularly given the positive associations with self-employment in view of its contribution to socio-economic life. Given the high occurrence of moderate psychiatric symptoms, it is plausible (from a Darwinian perspective) that psychiatric symptoms not only confer risks but can also be beneficial for the individual. For the field of psychopathology, it is important to study the potential benefits of demonstrating a high level of ADHD symptoms [21, 32, 59, 60] across the lifespan [11, $14,27,61]$. Such a focus on the value (rather than the cost) of ADHD is at the heart of a recent stream of literature in the field of psychiatry (i.e., Darwinian Psychiatry), which argues that the persistence of such mental 'disorders' serves a purpose [27, 61-63]. According to this research stream, psychiatric symptoms or genetic variations that are mostly or currently disruptive for an individual's work and private life can-under some circumstances or in mild forms-be beneficial for the 'adaptation' or survival of the individual. Hence, (young) adults who experience mild to severe ADHD symptoms may benefit rather than suffer from them provided they find ways to cope with the 
negative consequences in general and in relation to an entrepreneurial context [22]. Benefits may be particularly salient when individuals with ADHD symptoms find a suitable work environment, such as self-employment, where the 'disorder' is not harmful but instead can be valuable and help them to function well in society $[21,27$, 61].

Although the present study only investigates one single outcome, self-employment as a possibly positive aspect of ADHD symptoms, it highlights some promising avenues for future research. First, the current data do not enable us to examine the association between ADHD symptoms and the performance of self-employed individuals. The question that arises is whether self-employed individuals who score higher on ADHD symptoms also have better-performing ventures [53]. Second, the decision to become self-employed may not be the only association with ADHD symptoms; underlying entrepreneurial behaviours such as risk-taking and proactivity may share this association [52]. ADHD symptoms may also have 'positive' associations with other socio-economic behaviours for occupational choice, such as in management and consultancy positions [24]. Third, to generalise the results of this study, it is worthwhile to examine the association between ADHD symptoms and self-employment in other, preferably nonEuropean, population-based cohorts. It is also important to distinguish between individuals with a different occupational status in the control group, including wage employment and unemployment. A first attempt is reported in our section on sensitivity analyses. For future research, it is important to distinguish between these (alternative) occupations to effectively examine the association with different control groups.

To conclude, our results indicate that the positive association between ADHD symptoms and the decision to become self-employed primarily hinges on the hyperactivity symptoms of ADHD, whereas the overall association between ADHD symptoms and self-employment is only significant in one of our two samples. For future research, it is important to understand how ADHD symptoms are associated with more specific self-employment and entrepreneurship behaviours, such as the level of risks taken or performance in self-employment or as a business owner. This research may enhance our understanding of the positive effects of ADHD symptoms or even 'destigmatise' ADHD as a disorder that always deserves treatment.

\section{Compliance with ethical standards}

Conflicts of interest The authors have no conflicts of interest to declare.

Ethical statement This study was conducted according to the guidelines in the Declaration of Helsinki. The STAGE cohort study was approved by the ethics committee of Karolinska Institutet, Stockholm, Sweden, and all participants provided written informed consent. The GUESSS study was in line with the Erasmus Research Institute of Management (ERIM) review board's standards and did not include clinical or patient data.

Open Access This article is distributed under the terms of the Creative Commons Attribution 4.0 International License (http://crea tivecommons.org/licenses/by/4.0/), which permits unrestricted use, distribution, and reproduction in any medium, provided you give appropriate credit to the original author(s) and the source, provide a link to the Creative Commons license, and indicate if changes were made.

\section{References}

1. Turner, R. Executive life: in learning hurdles, lessons for success. New York Times (Business Day). November 23, 2003. p.10.

2. Archer, D. ADHD: the entrepreneur's superpower. Forbes Magazine (Leadership). May 14, 2014.

3. Archer, D. ADHD: the high price of a quick, quick fix. Forbes Magazine (Leadership). January 6, 2014.

4. The Economist. In praise of misfits. Why business needs people with Asperger's syndrome, attention-deficit disorder and dyslexia. Econ. (Business, Schumpeter). June 2, 2012.

5. Barkley RA. Behavioral inhibition, sustained attention, and executive functions: constructing a unifying theory of ADHD. Psychol Bull. 1997;121:65-94.

6. Cantwell DP. Attention deficit disorder: a review of the past 10 years. J Am Acad Child Adolesc Psychiatry. 1996;35:978-87.

7. Conners CK. Attention-deficit/hyperactivity disorder-historical development and overview. J Atten Disord. 2000;3:173-91.

8. Biederman J, Petty CR, Monuteaux MC, Fried R, Byrne D, Mirto $\mathrm{T}$, et al. Adult psychiatric outcomes of girls with attention deficit hyperactivity disorder: 11-year follow-up in a longitudinal casecontrol study. Am J Psychiatry. 2010;167:409-17.

9. Biederman J, Petty CR, Evans M, Small J, Faraone SV. How persistent is ADHD? A controlled 10-year follow-up study of boys with ADHD. Psychiatry Res. 2010;177:299-304.

10. Larsson H, Asherson P, Chang Z, Ljung T, Friedrichs B, Larsson $\mathrm{J}-\mathrm{O}$, et al. Genetic and environmental influences on adult attention deficit hyperactivity disorder symptoms: a large Swedish population-based study of twins. Psychol Med. 2013;43:197-207.

11. Spencer TJ, Biederman J, Mick E. Attention-deficit/hyperactivity disorder: diagnosis, lifespan, comorbidities, and neurobiology. J Pediatr Psychol. 2007;32:631-42.

12. Faraone SV, Biederman J, Mick E. The age-dependent decline of attention deficit hyperactivity disorder: A meta-analysis of follow-up studies. Psychol. Med. 2006;36:159-65.

13. Wilens TE, Faraone SV, Biederman J. Attention-deficit/hyperactivity disorder in adults. JAMA. 2004;292:619-23.

14. Kooij JJS, Buitelaar JK, van den Oord EJ, Furer JW, Rijnders CAT, Hodiamont PPG. Internal and external validity of attentiondeficit hyperactivity disorder in a population-based sample of adults. Psychol Med. 2005;35:817-27.

15. Kuriyan AB, Pelham WE, Molina BSG, Waschbusch DA, Gnagy $\mathrm{EM}$, Sibley $\mathrm{MH}$, et al. Young adult educational and vocational outcomes of children diagnosed with ADHD. J Abnorm Child Psychol. 2013;41:27-41.

16. Raggi VL, Chronis AM. Interventions to address the academic impairment of children and adolescents with ADHD. Clin Child Fam Psychol Rev. 2006;9:85-111.

17. Loe IM, Feldman HM. Academic and educational outcomes of children with ADHD. J Pediatr Psychol. 2007;32:643-54. 
18. Kleinman NL, Durkin M, Melkonian A, Markosyan K. Incremental employee health benefit costs, absence days, and turnover among employees with ADHD and among employees with children with ADHD. J Occup Environ Med. 2009;51:1247-55.

19. Biederman J, Faraone S. The effects of attention-deficit/hyperactivity disorder on employment and household income. Medscape Gen Med. 2006;8:12.

20. Wilmshurst L, Peele M, Wilmshurst L. Resilience and well-being in college students with and without a diagnosis of ADHD. J Atten Disord. 2011;15:11-7.

21. Glass K, Flory K, Hankin BL. Symptoms of ADHD and close friendships in adolescence. J Atten Disord. 2012;16:406-17.

22. Lerner DA. Behavioral disinhibition and nascent venturing: relevance and initial effects on potential resource providers. J Bus Ventur. 2016;31:234-52.

23. Audretsch DB, Thurik R. What's new about the new economy? Sources of growth in the managed and entrepreneurial economies. Ind Corporate Change. 2001;10:267-315.

24. Thurik AR, Stam E, Audretsch DB. The rise of the entrepreneurial economy and the future of dynamic capitalism. Technovation. 2013;33:302-10.

25. Koellinger PD, Thurik AR. Entrepreneurship and the business cycle. Rev Econ Stat. 2011;94:1143-56.

26. Thurik AR, Carree MA, van Stel A, Audretsch DB. Does selfemployment reduce unemployment? J Bus Ventur. 2008;23:673-86.

27. Shelley-Tremblay JF, Rosén LA. Attention deficit hyperactivity disorder: an evolutionary perspective. J Genet Psychol. 1996;157:443-53.

28. Hartmann T. ADHD secrets of success: coaching yourself to fulfillment in the business world. 1st ed. New York: SelectBooks; 2002.

29. Verheul I, Block JH, Burmeister-Lamp K, Thurik R, Tiemeier H, Turturea R. ADHD-like behavior and entrepreneurial intentions. Small Bus Econ. 2015;45:85-101.

30. Flach F. Disorders of the pathways involved in the creative process. Creativity Res J. 1990;3:158-65.

31. Healey D, Rucklidge JJ. An investigation into the relationship among ADHD symptomatology, creativity, and neuropsychological functioning in children. Child Neuropsychol. 2006;12:421-38.

32. White HA, Shah P. Creative style and achievement in adults with attention-deficit/hyperactivity disorder. Pers Individ Differences. 2011;50:673-7.

33. Mäntylä T, Still J, Gullberg S, Del Missier F, Mantyla T, Del Missier F. Decision making in adults with ADHD. J Atten Disord. 2012;16:164-73.

34. Hesse M. The ASRS-6 has two latent factors: attention deficit and hyperactivity. J Atten Disord. 2012;17:203-7.

35. Lichtenstein P, Sullivan PF, Cnattingius S, Gatz M, Johansson S, Carlström E, et al. The Swedish Twin Registry in the third millennium: an update. Twin Res Hum Genet. 2006;9:875-82.

36. Friedrichs B, Wilmar L, Larsson H, Larsson J-O. Coexisting psychiatric problems and stressful life events in adults with symptoms of ADHD-a large Swedish population-based study of twins. J Atten Disord. 2012;16:13-22.

37. Furberg H, Lichtenstein P, Pedersen NL, Thornton L, Bulik CM, Lerman $\mathrm{C}$, et al. The STAGE cohort: a prospective study of tobacco use among Swedish twins. Nicotine Tob Res. 2008;10:1727-35.

38. Kessler R, Adler L, Ames M. The World Health Organization Adult ADHD Self-Report Scale (ASRS): a short screening scale for use in the general population. Psychol Med. 2005;35:245-56.

39. Sieger P, Fueglistaller U, Zellweger T. Entrepreneurial intentions and activities of students across the world. GUESSS Proj: Int Rep; 2011.
40. Kessler RC, Adler LA, Gruber MJ, Sarawate CA, Spencer T, Van Brunt DL. Validity of the World Health Organization Adult ADHD Self-Report Scale (ASRS) Screener in a representative sample of health plan members. Int J Methods Psychiatr. Res. 2007;16:52-65.

41. Barkley RA, Fischer M, Smallish L, Fletcher K. Young adult outcome of hyperactive children: Adaptive functioning in major life activities. J Am Acad Child Adolesc Psychiatry. 2006;45:192-202.

42. Jacob CP, Romanos J, Dempfle A, Heine M, WindemuthKieselbach C, Kruse A, et al. Co-morbidity of adult attentiondeficit/hyperactivity disorder with focus on personality traits and related disorders in a tertiary referral center. Eur Arch Psychiatry Clin Neurosci. 2007;257:309-17.

43. Gomez R, Corr PJ. ADHD and personality: a meta-analytic review. Clin Psychol Rev. 2014;34:376-88.

44. Knouse LE, Traeger L, O'Cleirigh C, Safren SA. Adult attention deficit hyperactivity disorder symptoms and five-factor model traits in a clinical sample: a structural equation modeling approach. J Nerv Ment Dis. 2013;201:848-54.

45. Zhao H, Seibert SE. The big five personality dimensions and entrepreneurial status: a meta-analytical review. J Appl Psychol. 2006;91:259-71.

46. Brandstatter H. Personality aspects of entrepreneurship: a look at five meta-analyses. Pers Individ Dif. 2011;51:222-30.

47. Dunn T, Holtz-Eakin D. Financial capital, human capital, and the transition to self-employment: evidence from intergenerational links. J Labor Econ. 2000;18:282-305.

48. Chlosta S, Patzelt H, Klein SB, Dormann C. Parental role models and the decision to become self-employed: the moderating effect of personality. Small Bus Econ. 2012;38:121-38.

49. Grizenko N, Paci M, Joober R. Is the inattentive subtype of ADHD different from the combined/hyperactive subtype? J Atten Disord. 2010;13:649-57.

50. Acosta M, Castellanos F, Bolton K. Latent class subtyping of attention-deficit/hyperactivity disorder and comorbid conditions. J Am Acad Child Adolesc Psychiatry. 2008;47:797-807.

51. Miller T, Nigg J, Faraone S. Axis I and II comorbidity in adults with ADHD. J Abnorm Psychol. 2007;116:519.

52. Thurik R, Khedhaouria A, Torrès O, Verheul I. ADHD Symptoms and Entrepreneurial Orientation of Small Firm Owners. Appl Psychol Int Rev. 2016. doi:10.1111/apps.12062.

53. Rauch A, Wiklund J, Lumpkin GTT, Frese M. Entrepreneurial orientation and business performance: an assessment of past research and suggestions for the future. Entrep Theory Pract. 2009;33:761-87.

54. Nigg JT. The ADHD response-inhibition deficit as measured by the stop task: replication with DSM-IV combined type, extension, and qualification. J Abnorm Child Psychol. 1999;27:393-402.

55. Young S. ADHD children grown up: an empirical review. Couns Psychol Q. 2000;13:191-200.

56. Bozionelos N, Bozionelos G. Attention-deficit/hyperactivity disorder at work: does it impact job performance? Acad Manag Perspect. 2013. doi:10.5465/amp.2013.0107.

57. Halmøy A, Fasmer OB, Gillberg C, Haavik J. Occupational outcome in adult ADHD: impact of symptom profile, comorbid psychiatric problems, and treatment: a cross-sectional study of 414 clinically diagnosed adult ADHD patients. J Atten Disord. 2009;13:175-87.

58. Halleland HB, Sorensen L, Posserud M-B, Haavik J, Lundervold AJ. Occupational status is compromised in adults with ADHD and psychometrically defined executive function deficits. J Atten Disord. 2015. doi:10.1177/1087054714564622.

59. Panksepp J, Scott EL. Reflections on rough and tumble play, social development, and attention-deficit hyperactivity disorders. 
In: Gullotta TP, editor. Meyer AL. Phys. Act. Across Lifesp. New York: Springer; 2012. p. 23-40.

60. White HA, Shah P. Uninhibited imaginations: creativity in adults with attention-deficit/hyperactivity disorder. Pers Individ Dif. 2006;40:1121-31.

61. Williams J, Taylor E. The evolution of hyperactivity, impulsivity and cognitive diversity. J R Soc Interface. 2006;3:399-413.
62. Brüne M, Belsky J, Fabrega H, Feierman JR, Gilbert P, Glantz K, et al. The crisis of psychiatry - Insights and prospects from evolutionary theory. World Psychiatry. 2012;11:55-7.

63. Troisi A, McGuire M. Darwinian psychiatry and the concept of mental disorder. Neuro Endocrinol. Lett. 2002;23:31-8. 